\title{
UN AÑO DE JUAN EMAR: EL ARTISTA DE VANGUARDIA EN UNA MODERNIDAD PERIFÉRICA ${ }^{1}$
}

\author{
Patricio Lizama A \\ Pontificia Universidad Católica de Chile. \\ plizama@uc.cl
}

RESUMEN/ ABSTRACT

En el presente artículo se analizan tres episodios de la novela Un Año. Primero se estudian las restricciones del artista en la sociedad colonial y la forma como resiste frente al poder. Luego se revela la uniformidad de la sociedad premoderna y la manera como se desarticula esta homogeneidad. Por último, se propone una verdadera poética del proceso creativo, la cual se inserta en la discusión sobre el papel y función del arte en la época.

PALABRAS Clave: artista, vanguardia, modernidad periférica.

This is an essay that focuses on three episodes of the novel Un Año. It begins by analyzing the restrictions of the artist in colonial society, and how he is able to endure in the face of power. It goes on to unveil the uniformity of pre-modern society, pausing to discuss ways in which such homogeneity can be disarticulated. Finally, this work proposes what really amounts to a poetics of the creative process, which is an intrinsic part of the discussion about the role and function of art during those times.

KEY WORDS: artist, avant, garde, peripherical modernity.

1 Este artículo es parte del proyecto de investigación "La vanguardia chilena en sus revistas (1920-1930): modernidad, poesía e intelectuales”, Fondecyt No 1090735. 
La mayoría de los estudiosos considera que el período de más grandes transformaciones en América Latina corresponde al lapso entre 1890 y 1920, décadas en las cuales existe una acelerada modernización que se manifiesta en lo económico y político, lo social y cultural. En 1910, Chile celebra su centenario y si bien entre las elites de la sociedad oligárquica adscritas al discurso ilustrado hay complacencia por la consolidación de una nación autónoma que exhibe variados signos de modernidad, entre los grupos emergentes surgen voces críticas que denuncian los problemas sociales y cuestionan la resistencia de los poderes hegemónicos de la sociedad tradicional a las propuestas de una cultura moderna.

Emar nace en 1893, de modo que crece en medio de estas disputas entre tradición y modernidad ${ }^{2}$, sin considerarse incorporado en el proyecto de un país que prioriza el desarrollo económico y que otorga a la cultura un papel que se expresa en contenidos y hábitos elitistas. En 1913, cuando apenas tiene veinte años, posee la certeza de vivir "fuera de lugar" en el Chile moderno de comienzos del siglo XX. Asume que nada tiene que hacer ni en su patria, pues "la nación joven no lo necesita" (Yáñez 137) ni en su familia, porque "soy para casi todos un inútil". Con un gesto romántico, rechaza la sociedad que lo excluye y se define como un ser "raro", poseído por un "abatimiento indescriptible", un extraño que "no encaja en el mapa cognitivo, moral ni estético" de su país (Bauman 27).

Los continuos viajes a Europa y dentro de su patria le hacen entender de modo cabal que si bien hay una matriz común de la modernidad, "no hay algo así como una única vivencia prototípica de ella, situada por fuera y por encima de los límites de la geografía, el tiempo, la clase social y las culturas locales" (Brunner 176). De este modo, elabora una mirada cosmopolita atenta a los cambios en metrópolis europeas -complejas, abiertas, móviles, con campos culturales autónomos. Al tomar distancia de sus raíces, alejado de su cultura de origen, elabora también una mirada nacional que indaga en los límites de las sociedades tradicionales - cerradas, estáticas, con campos culturales más dependientes- por lo que su visión de éstas es muy crítica.

2 El mismo año nace Vicente Huidobro, María Teresa Wilms -artista que se atrevió a desafiar el rol asignado a la mujer por la sociedad patriarcal y que terminó suicidándose en París en 1922- y Juan Guzmán Cruchaga, quien en sus poemas advierte la crisis de la modernidad y la ausencia de Dios. 
En este trabajo analizaremos tres episodios de la novela Un Año (1935), diario de vida cuyo narrador refiere los sucesos que le ocurren el primer día de cada mes del año, para explicitar de qué forma Emar aborda las restricciones, el trabajo escritural y la función ideológica del artista al interior de una modernidad periférica.

\section{MODERNIDAD Y ARTISTA EN CHILE: PODER Y RESISTENCIA}

El pintor de la modernidad descrito por Baudelaire se enfrenta a una realidad dinámica siempre en continuo movimiento y allí debe captar el momento efímero y contingente. Su desafío es instalarse en medio de lo fugitivo y de lo infinito, colocar su visión y su energía sobre lo pasajero para percibir lo eterno en lo transitorio del presente que pasa. Así, se convierte en una conciencia que recoge la multiplicidad de la vida, a veces en medio de ella, otras veces oculto al mundo. Aprehende una "instantánea" de los seres humanos en la corriente de la vida social moderna, de modo que su conocimiento, así como su representación, resultan en tramas discontinuas y fragmentarias, cambiantes y pluridimensionales, donde el instante contiene dentro de sí mismo, la posibilidad de "descubrir en cada uno de los detalles de la vida la totalidad de su significado" (Frisby 28$)^{3}$.

En Un Año, los sucesos del primero de abril colocan al protagonista ante un presente que pasa, una imagen momentánea que él observa a través de la ventana de su casa: el cortejo fúnebre de un amigo. Si bien este "fragmento fortuito" constituye una experiencia de la modernidad, según se revelará al final del segmento, ésta se encuentra situada en una sociedad periférica, lo que implica un desafío adicional para el personaje pues, además de tratar de captar lo efímero, debe desarticular los obstáculos que limitan su capacidad de visión del presente que pasa. El episodio se convierte en alegoría del doble quehacer del artista en una modernidad periférica.

La marcha fúnebre anuncia el paso del cortejo y el narrador "se precipita como un loco a su encuentro" (Un Año 29). Pero no logra observar bien lo que ocurre en el exterior "pues las ventanas de mi casa tienen, a la usanza colonial, gruesos barrotes de hierro" (Un año 29). Distanciado de su objeto, pues no posee la perspectiva exterior de la calle sino que está instalado detrás 
de la ventana, contempla en un verdadero umbral de la modernidad y oculto para el mundo. Ahí, el observador del paisaje callejero, desde un margen, contempla un presente transitorio que exige ser captado con la rapidez de una instantánea: ve pasar a "grandes, enormes, imponentes, cosacos", "cada uno sobre un gigantesco caballo negro", los que por sus insólitas dimensiones, "cubrían los edificios de enfrente, cubrían el cielo" (Un año 32).

La escena muestra una visión del paisaje urbano que está mediada por dos grandes dificultades. La primera son los "barrotes coloniales", sinécdoque de la pervivencia de lo pre-moderno, de la sociedad tradicional dominada por el hispanismo colonial católico, la cual, a través de la constelación de elite y los mecanismos y aparatos de su institucionalidad, coarta la diseminación de la modernidad e impide el florecimiento de nuevas subjetividades.

El narrador, impedido de salir a la calle, no puede acceder con amplitud al conocimiento de lo ocurrido, porque su campo de visión es estrecho, el encuadre para enfocar la mirada es restringido y su perspectiva resulta muy interferida y mediada. La ventana, en vez de facilitar el acceso al conocimiento de nuevas realidades, encarcela al artista tras los barrotes, limita su libertad de movimiento y le impide explorar más allá del territorio adjudicado. La ventana colonial se convierte así en sinécdoque de la sociedad que enclaustra al creador y le impide cumplir su tarea de dar cuenta del momento que pasa.

El segundo obstáculo son "los cosacos" y "los caballos", sinécdoque del poder militar y de la dictadura de Carlos Ibáñez, la cual se inicia en 1927 y culmina con su renuncia en 1931. El gobernante es doblemente aludido en esta escena: por su sobrenombre, "el caballo", y por su calidad de militar ${ }^{4}$. En términos culturales, el ibañismo concibe el sistema identitario como orgánicamente cerrado y reivindica la pureza de lo vernacular frente a una modernidad que negaría lo propio. Con esta perspectiva, el arte tiene como tarea ideológica la articulación de una identidad nacional basada en una esencia inconmovible, cuyas raíces se hallan en los antepasados indígenas, de modo que hay que "enderezar todos los cauces de la belleza", como se manifiesta en la época, lo que implica terminar con la imitación de modelos foráneos. Si el carácter nacionalista promovido por el Estado impregna al conjunto de las artes, la autonomía del campo cultural se debilita y las

4 Agreguemos que el gobierno de Ibáñez presionó y amenazó al padre de Emar, Eliodoro Yáñez, quien en 1927 se vio obligado a vender al gobierno el diario de su propiedad, La Nación, a un precio irrisorio. 
propuestas vanguardistas son excluidas y rechazadas con gran celo. Como la representación en algunos cuadros de Magritte, el gobierno de Ibáñez eclipsa la modernidad.

Las dos mediaciones que se interponen entre el narrador y el paisaje urbano lo obligan a asumir la tarea de desmontar el orden colonial y desactivar el poder de ocultamiento del gobierno dictatorial, porque allí donde hay tecnología de sujeción, allí también está "aquello que resiste, altera, muta esos regímenes normativos" (Giorgi y Rodríguez 11). Esta labor de resistencia, el narrador la realiza a través del lenguaje, pues la desmesura inicial de caballos y cosacos sustentada en la reiteración y gradación, la hipérbole y los epítetos -"grandes", "enormes", "imponentes", "gigantesco"- desaparece con el uso del oxímoron, las comparaciones y los diminutivos. Así, el último cosaco de gran estatura y el "gigantesco caballo negro", al alejarse, devienen "grande como un ratón", la carroza es chiquita y los deudos "iban ahí como hormigas, como hormiguitas... titas" (Un año 30).

Al deshacer los obstáculos, el narrador puede observar todos los elementos del paisaje moderno: "se veía el cielo. Ya aparecían los edificios en las proporciones de enfrente. Ya se veían enteros" (Un año 32). Los efectos derivados de esta metamorfosis son múltiples. El paisaje que se hace visible consagra el triunfo de la posición del protagonista que estaba en el margen: quien mira, a través de saberes y prácticas, logra desocultar la modernidad. El cortejo fúnebre se convierte en alegoría de la muerte de la sociedad tradicional y del gobierno ibañista; la desarticulación final del lenguaje indica la desaparición de los grupos dominantes y de las fuerzas retardatarias, de sus poderes y restricciones: todos ellos son rebajados y desalojados. La carnavalización se convierte en sátira del fin de una sociedad.

La visión de la modernidad revela una última imagen del protagonista. Si al comienzo del episodio mira hacia la calle, pero queda pegado a los barrotes coloniales "como un insecto en el radiador de un auto veloz" (Un Año 29), indicio del rebajamiento que el poder ejerce sobre el artista, pues, a la manera de Kafka, lo aliena, al final del episodio el creador se engrandece, ya que logra ver y expandir su mirada al desarmar los impedimentos que ocultaban la escena. El artista logra percibir el "auto veloz", metonimia de la modernidad, y si bien no sale de la cárcel y permanece oculto detrás de los barrotes, desde el margen puede realizar su trabajo deconstructivo. Esta posibilidad define de modo cabal el concepto emariano de arte: “QQué es el arte sino un estallido? ¿Qué es, qué puede ser sino un perpetuo descalabozamiento?" (Umbral 573). 


\section{SOCIEDAD Y NOVELA EN AMÉRICA LATINA}

El artista y la modernidad periférica son problemáticas que se complementan en los sucesos de diciembre. En abril, todo ocurre en la urbe, la experiencia moderna se representa a través de la aprehensión de la imagen de una instantánea, en cambio, en el último mes del año, la acción sucede en puertos que más bien se asemejan a aldeas, poseen un carácter premoderno y cuya representación asume la modalidad del panorama.

Los observadores se sitúan a diferentes distancias de su objeto, pues si en el primer caso existe una distancia espacial, en el segundo la distancia es espacial y temporal. El retrato también difiere, porque en abril percibimos un paisaje callejero, en cambio, en diciembre el retrato es de un puerto inserto en un paisaje. Por último, los barrotes también son distintos porque en los puertos visitados, las estructuras externas de la sociedad tradicional se han internalizado en sus habitantes: el ámbito público y colectivo se coloca en relación con el privado e individual.

El narrador hace un viaje en barco que comienza en Valparaíso y continúa por el norte de Chile, Perú y el sur de Ecuador. Al regresar, anota sus recuerdos de modo que el tiempo de la enunciación de la escritura es posterior al del viaje que desea contar. La mirada vuelta hacia el pasado, más que un tono reflexivo, adopta uno lúdico y así el relato resulta irónico y satírico.

El viaje, siempre definido por la aventura y el descubrimiento, el aprendizaje y la transformación del descubridor, resulta en este episodio una experiencia degradada. Los nueve puertos de tres países distintos son una mezcla de mundo rural con aldea tradicional y la semejanza entre todos ellos es precisamente lo sorprendente del viaje. Así, la aventura se torna monótona, porque el narrador se encuentra con geografías similares y con sujetos que han interiorizado disposiciones para actuar y percibir, valorar y pensar, las cuales les impiden abrirse a la modernidad: ellos construyen otros barrotes que configuran un enrejado reacio a lo nuevo.

Las sociedades visitadas son formaciones socioeconómicas que poseen rasgos inmutables y uniformes en su vida. Son estáticas, ajenas al dinamismo moderno, ya que en términos económicos y culturales, se hallan dominadas por la idea de estabilidad y el temor a lo nuevo. Con una economía de base agrícola, en ellas el presente se halla ligado al pasado y el tiempo regresa una y otra vez para iniciar y culminar siempre el mismo ciclo. Son homogéneas, porque todo lo que habita en ellas conforma un conjunto con intereses y aspiraciones similares, de modo que todo resulta muy normado, los individuos 
tienen un espacio reducido para el desarrollo de cualidades específicas e iniciativas libres y responsables y existe poca tolerancia a la diversidad. Son endogámicas, pues hay en ellas una conciencia colectiva y un pensamiento uniforme de líneas fronterizas muy claras que, cuando se siente vulnerado, se cohesiona. Así, sus ciudadanos rechazan la incorporación de todo sujeto no nacido en ellas y el que franquea estos límites es perseguido y excluido.

La vida basada en relaciones restringidas y limitadas, en una minuciosa vigilancia de las actividades e ideas del individuo y en la costumbre, limita la individualidad y los vínculos con quienes podrían disolver la rigidez. En este episodio, si el hombre intenta ejercer su libertad respecto a la matriz oficial para implementar algo ajeno a la producción legitimada, la propia sociedad activa sus aparatos represivos y lo anula con el castigo. Al extranjero que posee otros saberes, si hace públicas sus opiniones alternativas ante la elite dirigente, se le margina, pues ofende la conciencia colectiva basada en la tradición, en el saber consuetudinario que no es posible refutar. El pájaro errante que viene de afuera, aun cuando adopte la modalidad del canto local, es considerado un extraño y no sobrevive: "es alimento seguro, fatal, de serpientes, escorpiones... y otros bacterios" (Un año 107). En la cultura y en la naturaleza, todo remite a la protección de la identidad y al rechazo de lo foráneo ${ }^{5}$.

La manera de desarticular esta rigidez, al igual que en el episodio de abril, pasa por una resistencia ejercida en el lenguaje. La descripción reiterada y similar de todos los puertos revela la imposibilidad de singularizar los lugares; en otras ocasiones, la narración sirve para desrealizar hasta el absurdo lo percibido. En Antofagasta hay "calles de lana", "habitantes de lana", "árboles de lana” (Un Año 106), retrato alterado que desestabiliza la mimesis realista, el sistema de preferencias vigente y el horizonte de expectativas de la época. La ironía también se destaca, porque lo que aparenta ser elogioso (la "marcada diferencia [de la ciudad de Iquique] con las dos anteriores" (Un año 107), de Mollendo, "la cosa es de otro modo" (108), o de Pacasmayo, "iQué cambio!" (111) se convierte en un juicio negativo y burlón.

5 La uniformidad y la endogamia adquieren caracteres irónicos. Las aves "gritaban a un mismo tiempo y sin interrumpirse ni un segundo" (112); el pájaro nativo viaja "por las cinco partes del globo" (107), pero nunca es excluido en los países extranjeros y canta hasta que muere. 
La identidad del nombre de las ciudades se desarma con juegos de lenguaje, operación que deja ver fisuras por donde puede surgir la diferencia. Coquimbo es la "tierra de los cocos y de los guindos" y Antofagasta que antes "se gastaba", ahora "que es de lana, no se gasta" (Un año 106). La uniformidad se descentra por medio de la enumeración caótica que une planos incompatibles en el mundo sensible como lo animado y lo inanimado, lo humano y lo natural, lo normal y lo anormal. En Coquimbo son lanzados al mar el extranjero y un colchón que deja ver en su interior algodón y no cocos y guindos. En Antofagasta todo es de lana y de repente, "pasa y bosteza una estufa y agoniza un famélico fakir" (106). En Mollendo, como todo es muelle y blando, la realidad se torna fabulosa: sus habitantes se recuestan en "una rama... en la chimenea de una casa, en las olas del mar" (108).

La representación grotesca de estos espacios resulta otra manera de desarticular. La deformación de las realidades que resultan conocidas al hombre, la similitud que deviene anormal y provoca extrañamiento, el exceso y la metamorfosis de seres o cosas, la mezcla de lo familiar y lo monstruoso, el comportamiento fuera de lo normal que adquiere un carácter fabuloso, la alteración del orden de la naturaleza, todo ello tiene por objeto poner en crisis un orden con el sentido final de destruirlo y así edificar uno nuevo.

El viaje revela la dificultad para vivir y apropiar la modernidad. El narrador se traslada para buscar nuevas experiencias lejos de su geografía habitual, ir al encuentro de un territorio objeto del deseo, entrar en contacto con lo desconocido y ajeno, con lo otro. Lo descubierto, prácticas y discursos inscritos en la tradición, disposiciones heredadas que a modo de barrotes impiden la apertura a lo nuevo, defrauda sus expectativas por lo que debe recurrir al humor como mecanismo compensatorio de defensa y consuelo.

Al mismo tiempo, el viaje puede leerse como una alegoría de la creación del novelista chileno. Emar sostiene en 1935 que la poesía nacional "ya mil veces ha abandonado sus fondeaderos para lanzarse a alta mar, sin temor de perder de vista la costa" ("Resucita" 11). Al contrario, "los prosistas... prefieren costear, prefieren ir atisbando de caleta en caleta, volviendo la espalda a lo desconocido detrás del horizonte" ("Resucita" 11). El narrador de Un Año realiza un viaje "de caleta en caleta", pero lejos de interesarse en retratar lo externo con un enfoque ligado al color local, propone un relato que carnavaliza y satiriza la realidad descrita con una mirada que utiliza las propuestas emergentes. El "costeo" emariano es otro. 


\section{POÉTICA Y FUNCIÓN DE UNA ESCRITURA}

La reflexión acerca del artista y la modernidad es distinta en el mes de agosto, donde el narrador, aunque una vez más trabaja en la desarticulación del lenguaje, elabora una propuesta de escritura que tiene por objeto modificar la valoración de las palabras, revelar toda la riqueza de su polisemia y así postular un arte liberador.

El escritor peruano César Miró que vivió en Chile durante los años treinta, aparece como personaje en este episodio y a través de lo que le sucede, se propone una verdadera poética del proceso creativo, la cual se inserta en la discusión sobre el papel y función del arte en la época. Para comenzar, el narrador distingue dos modalidades de construcción del hombre de letras, las cuales, más que opuestas, son complementarias. Una corresponde al que vive y experimenta en medio de la ciudad, interpreta lo que ocurre y hace públicas sus opiniones en la plaza. La otra corresponde al que habita la torre, vive más retirado y con una perspectiva más reflexiva y meditativa, contempla la realidad con mayor distancia.

Miró, ligado a esta última variante, se aproxima al mundo a través de una doble mediación. El lee un periódico de cuyas páginas se desprende un "ligero murmullo universal" (Un Año 63) que si bien informa acerca de lo que ocurre, está mediado por la naturaleza de la comunicación periodística, centrada en la novedad, la proximidad y la verificabilidad. La otra mediación es la del instrumento con que se transmiten estas noticias, es decir, el lenguaje de carácter convencional utilizado en la comunicación cotidiana que difunde las novedades de la prensa. Este tiende a expresar una significación unívoca, reitera construcciones establecidas, utiliza significados compartidos y configura un discurso normalizador.

El personaje atiende al "murmullo universal" que transmite el periódico, pero luego se deshace de la palabra ajena, del "murmullo" y del lenguaje que lo comunica, acto que en la novela se revela a través de una imagen muy elocuente. Miró se tiende en la cama para leer el diario y al levantarlo "todas las letras de todas las palabras de la primera página... se desprendieron y cayeron" (Un año 63) de forma que él queda "cubierto de miles y miles de letras desparramadas sin significado ni razón” (63). Al caerse las letras, 
desaparece la información, las noticias se diluyen, el lenguaje se desarticula y la página queda en blanco ${ }^{6}$.

El desprendimiento indica el derrumbe de un mundo, señala el colapso de una época y sus fundamentos y ante el vacío, el personaje se transforma de lector a escritor y se enfrenta a una nueva tarea: recrear el mundo, transfigurarlo y otorgarle un nuevo significado a partir de una verdadera danza de significantes. Para ello, necesita desarraigar las palabras, arrancarlas de sus conexiones y significados habituales pues cada una de ellas está unida a una serie de significaciones veladas, a asociaciones en la oscuridad de la conciencia, a una connotación afectiva, moral, política, que siempre está cargada de valoraciones, voces y acentos opuestos porque todo acto verbal se instala en cadenas previas de enunciados y nunca lo hace en forma neutra ${ }^{7}$.

Una vez despojadas las palabras de esa carga ideológica y desde la identidad material de la lengua, el escritor debe elaborar un lenguaje que con diferentes connotaciones y renovadas marcas ideológicas, pueda nombrar la realidad con mayor exactitud. El asume el lenguaje desde el dialogismo de los enunciados, da un nuevo orden a los signos y les devuelve un carácter único, por tanto, necesita regresar a la palabra para transformarla, hacerla insustituible y otorgarle un acento propio. Su tarea consiste en volver a hilvanarlas, articularlas en una escritura singular, en un tejido que comunique un pensamiento nuevo y represente a los hombres. El artista desarrolla así un proceso escritural que implica desmontar/desarmar y luego construir/ comunicar.

Entre las letras desparramadas, Miró “coge dos 'A', que ha de ser... las que nombran a 'SU ALTEZA", pero también pueden corresponder "a una 'RAMERA"” (Un año 64). Estas dos opciones, valoración de lo subalterno exactamente opuesta a lo hegemónico, indican que el escritor se cuestiona el contenido y la función ideológica del arte, se interroga acerca de qué intencionalidad darle a la escritura, disyuntiva que puede plantearse en tres planos complementarios: qué realidades comunicar, la esfera de lo alto o de lo bajo; qué sujetos representar, el del poder o el del margen y cómo abordar

6 Esta imagen tiene un parentesco con la propuesta dadaísta para hacer un poema. Ellos sugieren tomar un periódico, recortar cada palabra de un artículo, meterlas en una bolsa y luego sacarlas una a una. El poema se configura a partir del orden en que salen las palabras. Ver Dadá Manifiesto sobre el amor débil y el amor amargo.

7 Ver Drucaroff, Mijail. 
todo ello, risa o seriedad. Ello porque estas dos letras A pueden corresponder a la palabra "SU ALTEZA" y con ironía se podría narrar su matrimonio, o a la palabra "RAMERA" y con ella se podría contar el drama de su suicidio. Con la "s" y la "e" puede referirse con burla a "S.E", el Presidente de la República, o bien denunciar lo ocurrido con "los sepulcros violados anoche" o los sufrimientos de los "esclavos" que aún existen en el siglo XX (64).

Las opciones anteriores no son vistas como excluyentes. El escritor puede cuestionar las creencias establecidas y el sistema operante, los grupos hegemónicos y el mundo burgués, y asimismo, representar las problemáticas de minorías y sectores postergados, las luchas del proletariado y las técnicas de sujeción y normalización ejercidas por el poder disciplinario: puede contribuir a la preservación del poder efectivo de un grupo o contribuir a derribarlo.

Situado en este umbral inestable, la postura de Miró la entendemos como alternativa a las posiciones disponibles para el creador en el campo artístico de los años treinta. Una es el color local fundado en un sistema identitario cerrado que postula la necesidad de representar el carácter nacional a través de realidades exteriores y rasgos diferenciales. Otra es la del realismo socialista que, anclado en un relato emancipador, otorga al arte una función política orientada al esclarecimiento de la dominación y el enfrentamiento de clases, utiliza una estética prescriptiva basada en la reproducción mimética y promueve la participación de intelectuales orgánicos al proyecto centralizado.

El escritor peruano se aleja de ambas posiciones y propone, en cambio, la necesidad de concebir al artista como un intelectual que rechaza la imposición de la lógica política y la consiguiente resignación del pensamiento crítico, porque entiende que éste es, por definición, autónomo: "autonomía y crítica son dos rasgos que se presuponen y la exclusión de uno inevitablemente pone en peligro al otro" (Sarlo 209). Esta postura "no tiene como consecuencia necesaria el retiro de la política y el desdén por las cuestiones públicas" (Sarlo 210). Por el contrario, sostiene Sarlo, sin una "relación tensa con la política, en la que el pensamiento crítico resista la expansión colonizante de los intereses inmediatos pero, al mismo tiempo, no considere una virtud sustraerse a los problemas que éstos le plantean, parece difícil pensar la práctica intelectual crítica" (210).

La posición asumida por Miró resulta así una alternativa que adoptan varios artistas de la época los cuales, sin renegar de la necesidad de transformar la sociedad, poseen un juicio crítico ante el dogmatismo y la 
simplificación analítica de la diversidad humana y los procesos sociales ${ }^{8}$. Este planteamiento encontrará una formulación orgánica en el manifiesto Por un arte revolucionario e independiente de Breton y Trotsky (1938), donde afirman que el arte "no puede consentir sin rebajamiento en plegarse a ninguna directiva extraña y en venir a llenar dócilmente los marcos que algunos creen poder asignarle, con fines pragmáticos extremadamente cortos" (157). En razón de ello, agregan que la libre elección de los temas del arte y la ausencia de censura para explorarlos "constituyen para el artista un bien que tiene derecho a reivindicar como inalienable. En materia de creación artística, importa esencialmente que la imaginación escape a toda constricción, no se deje bajo ningún pretexto imponer derroteros" (157-158).

La autonomía, la permanente apertura, el estado de alerta constituyen la base para la tarea del escritor, aspectos que se formulan en la escena final. Miró visita la casa del narrador y de su ropa caen algunas letras, la "f", "t", "o", la ínfima "i", y esta última permanecerá en el umbral como un "centinela" para impedir las "preocupaciones domésticas" o "las visiones callejeras" (Un Año 65). La "i”" ocupa el mismo lugar donde se sitúa siempre el artista emariano, el umbral, y cumple la misma función: el que mira y observa el horizonte, el que interpreta lo por venir y convierte a la literatura en un conocimiento de lo aún no sucedido. Si agregáramos la " $n$ ", índice de lo múltiple, podríamos articular la palabra infinito y pareciera que precisamente, la ausencia de esta vocal entre las ropas de Miró, revela los límites del creador en la aprehensión de la realidad y la fisura de todo discurso que, en cuanto se enfrenta a un absoluto, se asume como incompleto, provisorio y aproximativo.

La posición emariana entonces se distancia del color local y del realismo socialista para postular un pensamiento crítico que autónomo y situado, se enfrenta al infinito. No es casual la opinión de Emar en 1935 acerca del panorama literario chileno; para él, lo importante es que "cada día se levanta una nueva vela y se aleja sin miedo hacia lo desconocido, hacia el infinito y eso me basta" ("Resucita" 11). 


\section{PALABRAS FINALES}

El arte y la literatura de vanguardia en la modernidad periférica se convierten en un instrumento esencial para descubrir los pliegues más ocultos de lo propio, de nuestros conflictos íntimos y colectivos. Al mismo tiempo, sirven para desmontar la cultura colonial y los enclaves de poder que a través de diversos mecanismos normalizadores obstaculizan la emergencia e instalación de lo nuevo.

La función del escritor no pasa por una denuncia abierta de los conflictos político-sociales ni por la representación de sujetos subalternos excluidos del proyecto nacional. Tampoco por una mímesis imitativa de lo real que busca poner en evidencia las inequidades del sistema político-social y así crear una conciencia y una conducta nuevas que sirvan para cambiar la sociedad.

La propuesta emariana, independiente, pero situada en su época, consiste en un trabajo de resistencia al poder, el cual se realiza desde el lenguaje. Él asume que las palabras están enclaustradas en significaciones que ocultan y falsean la realidad y por ello las desarma, las abre para que emerja desde ellas toda su polisemia y con esta riqueza se pueda modificar su valoración. La escritura se torna estrategia de desfiguración y anomalía contra las producciones normativas.

Emar, a través del diario de vida, desautomatiza las percepciones anquilosadas -parodia las convenciones temporales del género, satiriza el apego a fórmulas artísticas, la rigidez de las instituciones que las enseñan y la falta de autonomía en la sociedad periférica- y así genera perspectivas y conciencias nuevas capaces de subvertir el orden. Por ello, confiesa que, si bien no ve cómo hacer "estas artes para la multitud", asume que "desde hace ya tiempo se está haciendo revolución -en el sentido que quieras- en todas las artes" (Montecinos 183). El arte se convierte en umbral de extrañeza y revelación de nuevos pensamientos, porque Emar busca realizar un arte liberador, que sea un estallido capaz de intensificar el instante, encontrar todas las sugerencias de eternidad que este contiene y abrirse a la dimensión intensiva de lo transitorio para "imprimirle a la contingencia una infinita reverberancia" (Hopenhayn 133). Escribir es un devenir, siempre inacabado, siempre en curso y por tanto, una forma privilegiada de dar cuenta de cómo en la modernidad, todo lo sólido es algo que deviene, pasa y se desvanece en el aire. 


\section{BIBLIOGRAFÍA}

Bauman, Zigmunt. La posmodernidad y sus descontentos. Madrid: Akal, 2001.

Brunner, José Joaquín. "Modernidad”. Términos críticos de sociología de la cultura. Carlos Altamirano, ed. Buenos Aires: Paidós, 2002. 173-180.

Breton, Andre y Leon Trotsky. "Por un arte revolucionario e independiente". Antología (19131966). Selección y prólogo, Marguerite Bonnet. México: Siglo XXI, 1989. 154-161.

Drucaroff, Elsa. Mijail Bajtín: la guerra de las culturas. Buenos Aires: Almagesto, 1996.

Emar, Juan. Un año. Santiago: Zig-Zag, 1935. "Resucita escritor". Noreste 11 (1987): 11.

Umbral. Primer Pilar. El globo de cristal. Santiago: Dibam, 1996.

Frisby, David. Fragmentos de la modernidad: teorías de la modernidad en la obra de Simmel, Kracauer y Benjamin. Madrid: Visor, 1992.

Giorgi, Gabriel y Fermín Rodríguez, comps. "Prólogo". Ensayos sobre biopolítica. Excesos de vida. Buenos Aires: Paidós, 2007. 9-34.

Hopenhayn, Martin. Después del nihilismo. De Nietzsche a Foucault. Santiago: Andrés Bello, 1997.

Montecinos, Sergio. Entre músicos y pintores. Santiago: Amadeus, 1985.

Picón-Salas, Mariano. Regreso de tres mundos. México: F.C.E., 1985.

Sarlo, Beatriz. "Las formas del honor". Tiempo presente. Notas sobre el cambio de una cultura. Buenos Aires: Siglo XXI, 2001. 195-229.

Siete manifiestos Dada. Barcelona: Tusquets Editores, 1981.

Yáñez Bianchi, Álvaro. M[i] Viida]. Diarios (1911-1917). Transcripción, edición e introducción Thomas Harris, Daniela Schütte y Pedro Pablo Zegers. Santiago: Dibam-Lom, 2006. 